LETTER

If you have a burning desire to respond to a paper published in EM, why not make use of our "rapid response" option?

Log on to our web site (www.emjonline. com), find the paper that interests you, and send your response via email by clicking on the "eletters" option in the box at the top right hand corner.

Providing it isn't libellous or obscene, it will be posted within seven days. You can retrieve it by clicking on "read eletters" on our homepage.

The editors will decide as before whether to also publish it in a future paper issue.

\section{Use of cut endotracheal tubes should be avoided in the initial resuscitation of the burned patient}

The use of cut endotracheal tubes is already a contentious issue amongst anaesthetists. ${ }^{1}$ We wish to point out a potentially life threatening hazard when they are used in the emergency department during the initial resuscitation of the thermally injured patient.

Often these patients are intubated early if there is any indication of inhalational injury or facial burns. This is because subsequent oedema of the face and larynx can compromise the airway ${ }^{2}$ and render intubation difficult or impossible.

If a cut endotracheal tube has been used to secure the airway in this situation and there is subsequent facial or airway swelling, the proximal end of the endotracheal tube may become positioned within the oropharynx making access to it difficult. Worse still, if proximally secured, the distal end may become dislodged from the larynx. At this stage it may be extremely difficult to re-intubate the patient or exchange the tube for a longer one.

As these patients are often transferred to specialist burns units, the consequences of this occurring mid-transfer would be catastrophic.

As a tertiary referral centre for burns we often receive patients directly from emergency departments. It has, in the past, been necessary for us to perform quite hazardous tube changes on these patients.

We now routinely ask that all referring emergency departments ensure that any burns patient intubated with a cut endotracheal tube has it exchanged for an uncut one before transfer and we recommend that uncut endotracheal tubes only are used in the initial resuscitation of the burned patient.

M A Gillies, S Krone, K Sim Department of Anaesthesia, Queen Victoria Hospital, Holtye Road, East Grinstead, Sussex
Correspondence to: $\operatorname{Dr} M$ A Gillies; michaelgillies@yahoo.co.uk

\section{References}

1 Moyser LV. To cut or not to cut. Anaesthesia 1993;48:832

2 Lee-Chiong TL. Smoke inhalation injury. Postgrad Med 1999; 105:55-62.

\section{BOOK REVIEWS}

\section{Pediatric procedural sedation and analgesia}

B Krauss, R M Brustowicz, editors. (PP 327; \$39.95). Lippincott Williams and Wilkins, 1999. ISBN 0-683-30558-1.

As all who deal with children are well aware, over the past 10 years it has become unacceptable practice to physically restrain children for painful and non-painful procedures. There have been changes to the law with the Children's Act and the recent Human Right's Act to further constrain us and tie our own hands, alongside a growing demand from parents and children that a more humane approach is needed. This means we have to replace physical with pharmacological restraint.

This book is an American multi-authored text edited by an anaesthetist and an emergency physician from Boston Children's Hospital. It claims to contain everything you wanted to know about sedation in children but were afraid to ask-and it does. It is well written and easy to read. It gives tons of information on drugs and techniques, occasionally dropping into the text real life horror stories of sedation mismanagement, just to make sure we treat these techniques with the respect they deserve. The book is divided into three sections looking at scientific foundations, general management principles, and finally sedation for non-elective procedures.

The first two sections of the book are excellent. They extensively cover the physiology and pharmacology of sedatives and analgesics and discuss issues of consent, assessment, how to monitor these patients for adverse events and how to determine adequate recovery. The last section of the book advocates using sedation for many procedures that in the UK would automatically be done under general anaesthesia. This probably reflects a difference in culture and financial constraints on the two sides of the Atlantic. My main criticisms of the book are that like all multi-authored texts it is a little repetitive (but not excessively). Some of the drugs recommended are not available in this country (cetacaine, sufentanil), and some may be unavailable in the United States (Ametop) and so their role is not discussed. It occasionally advocates use of anaesthetic induction agents in doses that would produce anaesthesia, and as an anaesthetist this puts shivers up my spine.

Although this text is firmly aimed at American medical practice, it has much to recommend itself to anyone who has to perform procedures on children. Its aim is to advance the overall safety of sedation in children, which it goes a long way towards. Although distraction and relaxation are mentioned as techniques of enhancing or avoiding pharmacological restraint, it has little of the theory or description of their use. The differing backgrounds of the two editors has created a book that has a wider appeal, and should not be regarded as just for anaesthetists or accident and emergency physicians. It fills an important gap in the market and is eminently affordable.

M Cunliffe

Alder Hey Children's NHS Trust, Liverpool, UK

\section{Review of manual of emergency airway management}

R M Walls, editor in chief. (Pp256; \$42.95) Lippincott Williams and Wilkins, 2000. ISBN 0781726166

The front cover of this book bears the words: "Companion manual to the National Emergency Airway Management Course".

It is in this role that the book's design and concept was developed. It is not surprising therefore that the book achieves its maximum potential when used in that role. This is particularly evident in those chapters such as "Special devices for the difficult or failed airway" where complex psychomotor skills are described in print. Although the illustrations are good and the descriptions of the skills are as clear and concise as has been managed anywhere, these cannot replace the practice of those skills that the course permits. The combination of the manual and the course is strongly recommended as a powerful learning experience by this reviewer.

Even taken without the course the book itself is well worth owning. It fully lives up to its own description of itself as "the first and only complete guide to emergency airway management"

The chapters are logical in their sequence and offer a stepwise guide through decision making and practical procedures in emergency airway management. They have clearly been written by people sympathetic to the needs of adult learners. Examples of this sympathy include the airway algorithms, which are clear, binary and linked together seamlessly; the mnemonics which are few and easily remembered; the tips and pearls section at the end of many of the chapters (which serve in addition to emphasise and underline the experience of the authors).

Some differences in practice between North America and the United Kingdom are apparent. A specific example lies in the use of pretreatment drugs before rapid sequence intubation. A more general example lies in the

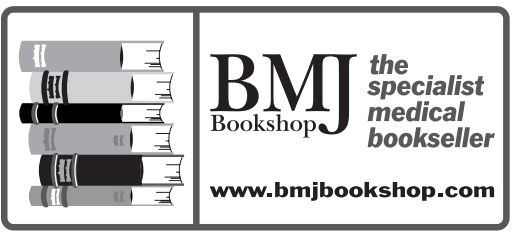


contrast between the roles and the relationships of emergency physicians and anaesthetists on either side of the Atlantic. These differences are most usefully seen as a trigger for reflective debate rather than as a reason to view the book as not applicable to UK practice. It most certainly is applicable to UK practice and would be useful reading for every trainee in anaesthesia, ITU, and accident and emergency.

A McGowan

St James's University Hospital, Leeds, UK

\section{The clinical practice of emergency medicine, 3 rd edn}

A Harwood-Nuss, editor. (\$189). Lippincott Williams and Wilkins, 2001. ISBN 0-7817. $1680-2$

While it is often said that those that can, do, and those that can't, teach, one gets the impression that the authors of this textbook not only work at the "coalface" of A\&E medicine but also teach with authority. The wide ranging subject material is approached from the more clinically relevant "presenting complaint" viewpoint rather than the usual diagnostic categories, giving an exceptionally practical orientation to the book. Essentially a reference book it enters a competitive market but offers a far more readable format than its larger equivalents.

The book aims to cover not only clinical information but also management and administrative issues. The text is clear with mainly line diagrams as illustrations. A rapid interrogation of the index proved the referencing reliable and relevant. I found the inclusion of "common pitfalls" under each section heading to be a useful and insightful feature. Perhaps less helpful are the sections on patient disposition, written largely from the North American perspective. Many of the issues raised may, however, still be of interest to a wider audience. The book is largely successful in its ambitious remit to provide a reference that is both comprehensive and accessible.

This would be a useful book to have around an A\&E department and may also prove valuable for those looking for a readable reference in preparation for both entry and exit examinations

Having received my "reviewer's copy" I am no longer in the market for a reference book in A\&E medicine. If I were, I might well buy this one!

D Pedley

Aberdeen Royal Infirmary, Aberdeen AB25 2ZN

\section{Child safe: a practical guide for preventing childhood injuries}

M A Brandenburg. (Pp228; \$14). Three Rivers Press, 2000. ISBN 0-6098-0412-X

Child safe is a book officially endorsed by the American Academy of Emergency Medicine written by a doctor who is a practicing emergency physician in a trauma emergency centre in Tulsa, Oklahoma. It is written for the nonmedical audience and draws on the author's considerable experience of trauma and illness in childhood. It is suggested reading for parents, grandparents, and carers of children.

The book is divided into two main sections termed "Non-age related injuries", which includes cars, fires, and toys, and "Age related injuries" including infants, toddlers and preschoolers, and school age children and the types of injuries that specifically befall them. The third part is a list of American product recalls and child safety resources such as the Farm Safety Association.

Although a lot of the general points are made well, there are two main problems with the book. The first is that this is essentially a book for an American readership concerning American products and relating to the American healthcare system. Therefore, it would be of less value in Europe. The second is the negative tone throughout the book rendering any spontaneity or adventure in childrearing almost impossible.

It is a book to be read in conjunction with Swallows and Amazons to provide a balanced view of the dangers of childhood. While not wishing to minimise how great these are, it is also true that books such as these can scare parents, grandparents, and carers into timidity themselves and an inability for their charges to explore or have any fun.

In short, a book to read but possibly not to re-read, for every zealous parent.

This book is intended for carers and is not a required addition for a medical library or for the $E M J$ readership.

D Hulbert

Emergency Department, Southampton General Hospital, Southampton, UK

\section{NOTICES}

\section{Reducing waits in A\&E: search for evidence}

The University of Warwick are conducting a systematic literature review of the evidence for interventions aimed to reduce waiting time (total time in A\&E, wait to see a doctor, wait for results, wait for admission, "trolley wait") and attendance in accident and emergency departments. This project is funded by the Department of Health. If you have undertaken any such innovations and have audited or evaluated the changes (or are aware of anyone who has done so) then please contact Dr Matthew Cooke, Project Lead, Centre for Primary Health Care Studies, School of Health and Social Studies, The University of Warwick, Coventry CV4 7AL, UK; m.w.cooke@warwick.ac.uk.

\section{Medic 1 Trust Fellowship}

The Medic 1 Trust Fellowship is awarded to facilitate education or research in the field of accident and emergency medicine and may be used for associated travel. The fellowship is awarded to a doctor or nurse currently working in the field of accident and emergency medicine. The value of the award will be a maximum of $£ 2500$. A maximum of one medical scholarship and one nursing scholarship will be made every year. Applications must be received by 28 February 2003. For further information, please write to: Chairman of the Medic 1 Trust, c/o Maclay Murray \& Spens Solicitors, 151 Vincent Street, Glasgow, G2 $5 \mathrm{NJ}$ 